University of New Orleans

ScholarWorks@UNO

Physics Faculty Publications

Department of Physics

2001

\title{
Multilayer MIM inversion of AEM data: Theory and field example
}

Clyde J. Bergeron Jr

University of New Orleans

Juliette W. Ioup

University of New Orleans

Yan Wu

Univerity of New Orleans

George E. loup

University of New Orleans

Kenneth W. Holladay

University of New Orleans

Follow this and additional works at: https://scholarworks.uno.edu/phys_facpubs

Part of the Physics Commons

\section{Recommended Citation}

Geophysics 66, 125 (2001)

This Article is brought to you for free and open access by the Department of Physics at ScholarWorks@UNO. It has been accepted for inclusion in Physics Faculty Publications by an authorized administrator of ScholarWorks@UNO.

For more information, please contact scholarworks@uno.edu. 


\title{
Multilayer MIM inversion of AEM data: Theory and field example
}

\author{
Clyde J. Bergeron, Jr.*, Juliette W. loup*, Yan Wu*, \\ George E. loup*, and Kenneth W. Holladay*
}

\section{ABSTRACT}

This paper presents a multilayer generalization of an algebraic method of inverting frequency-domain airborne active electromagnetic (AEM) data in terms of 1-D layered earth models. The processing of the AEM data, which includes a recalibration procedure, is also outlined. The inversion is applied to synthetic fields generated from a multilayer model which is intended to approximate a measured conductivity profile of the water column in the Gulf of Mexico and to measured AEM data from a survey of the Barataria Bay estuary region of the Louisiana Gulf of Mexico coast. The inversion results from the synthetic data are in good agreement with the forward model. The conductivities calculated from the inversions of measured AEM data are compared to ground- and water-based measurements. The depth variations of the calculated electrical conductivities in the nearshore Gulf waters are in good agreement with measurements of conductivity versus depth by conductivitytemperature-depth (CTD) casts at several points on the over-the-water portion of two flight lines.

\section{INTRODUCTION}

A frequency-domain airborne active electromagnetic (AEM) system determines ground (and water) conductivity by generating low-frequency electromagnetic fields and simultaneously measuring the induced secondary field whose strength is a function of the conductivity of the ground below the sensor (Fountain, 1998). The measured fields are responding to a volume average over the lateral footprint of the sensor, which depends on the flight height and the depth of penetration of the field, which in turn depends on the conductivity and the frequency of the field (Kovacs et al., 1995). Various schemes have been proposed for inverting the AEM fields to obtain layer thicknesses and conductivities (Sengpiel, 1983; Bergeron, 1986; Ellis, 1998).
The AEM field data used in this analysis are part of the results of a survey of Barataria Bay, Louisiana. The survey was conducted by U.S. Navy personnel based at Stennis Space Center, Mississippi, using a Naval Research Laboratory AEM system (Pelletier and Wu, 1989; Mozley et al., 1991; Pelletier and Holladay, 1994). A primary field waveform was digitally constructed from cosine functions of six frequencies: 29970 , $11670,4530,1770,690$, and $270 \mathrm{~Hz}$. The amplitude and phase of the secondary fields at these frequencies were determined by digitally convolving the measured secondary field with the original cosine functions.

\section{MIM THEORY}

The total field resulting from an AEM source near a conducting medium can be modeled as a primary dipole field plus a secondary field generated by induced currents in the conducting medium. Sommerfeld (1909) provided the formal solution to this problem. The resultant secondary field is complex with both inphase and quadrature components and is given in terms of integral expressions developed by Sommerfeld (Frischknecht, 1967).

The modified image method (MIM) is an algebraic representation of the secondary field (Bergeron, 1986). In the MIM representation, the source of the secondary field is an image of the primary dipole, the system transmitter coil. The image dipole is located at a complex depth below the earth's surface. Thus MIM is a version of complex image theory for which Wait (1991) has given an informal historical survey. Figure 1 illustrates this model. The coil spacing is $\rho$, and $h$ is the altitude of the bird. Note that

$$
\begin{gathered}
R=\left[2 h+2 \delta_{\mathrm{eff}}\right] / \rho, \quad \delta_{\mathrm{eff}}=(1-i) \delta_{1} Q / 2, \quad \text { and } \\
\delta_{1}=\left[2 / \mu \sigma_{1} \omega\right]^{1 / 2},
\end{gathered}
$$

where $\delta_{1}$ is the first layer skin depth, $\delta_{\text {eff }}$ is the effective skin depth, $\mu$ is the permittivity, $\sigma_{1}$ is the first layer conductivity, $\omega$ is the frequency, and $Q$ is Wait's multilayer correction factor (Wait, 1951). For a two-layer model (a single layer plus a 
bottom half-space),

$Q_{12}=\left[c_{12}+\tanh (1+i) y_{1}(f)\right] /\left[1+c_{12} \tanh (1+i) y_{1}(f)\right]$,

where $y_{1}(f)=d_{1} / \delta_{1}(f), d_{1}$ is the first layer thickness, $f$ is the AEM frequency in hertz, $\sigma_{1}$ is the first layer conductivity in siemens/meter, and $c_{12}=\left(\sigma_{1} / \sigma_{2}\right)^{1 / 2}$ [or more generally $c_{i j}=\left(\sigma_{i} / \sigma_{j}\right)^{1 / 2}$ (Wait, 1951)]. For a half-space, $Q=1$. For $c_{12} \simeq 1$ and/or $d_{1} \gg \delta_{1}$, then $Q_{12} \simeq 1$. For $d_{1} \ll \delta_{1}$, then $Q_{12} \simeq \delta_{2} / \delta_{1}$.

$R$ is the primary computational quantity of MIM theory. For a horizontal coplanar coil configuration, the ratio of the secondary and primary fields $H_{s} / H_{p}$ is given by (Bergeron, 1986)

$$
H_{s} / H_{p} \equiv Z=\left(2 R^{2}-1\right) /\left(1+R^{2}\right)^{5 / 2} .
$$

The primary dipole and the measured/calculated component of the secondary field are vertical. Computation of $Z$ constitutes the forward calculation of the MIM field from the model parameters. This result is approximately correct only for $A=2 h / \delta>1$ (Bergeron, 1986; Wait, 1991).

The inverse relationship which gives $R$ in terms of the measured data field $Z($ data $)$ is given as follows (Bergeron et al., 1989). First, let $t=[Z(\text { data }) / 2]^{1 / 3}$. Then the inverse relationship is

$$
\begin{aligned}
R= & (1 / t)-t-(9 / 8) t^{3}-(31 / 12) t^{5} \\
& -(2675 / 384) t^{7}+O\left(t^{9}\right) .
\end{aligned}
$$

The model parameters are embedded in $\delta_{\text {eff }}$ [see equation (1)], which is extracted from $R$.

The residual differences between the MIM field given by equation (3) and the Sommerfeld field, which is calculated

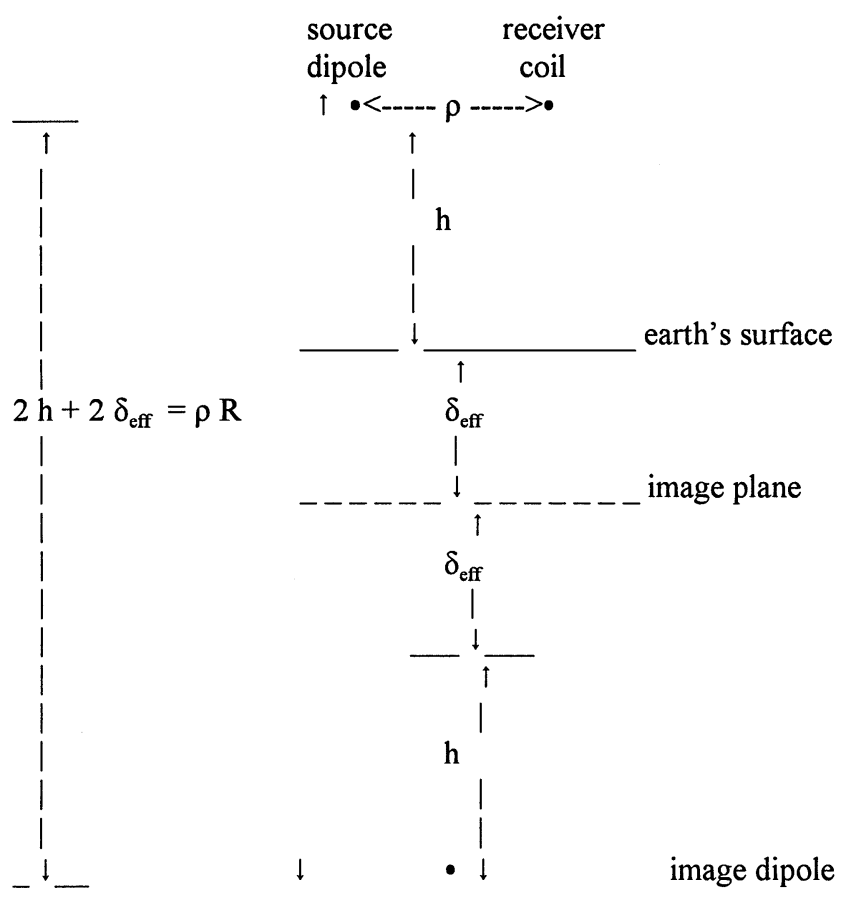

FIG. 1. MIM geometry for AEM. Relative locations of the transmitting dipole (coil), receiver coil, and image dipole; $h$ is the altitude of the bird, $\rho$ is the coil spacing, $\delta_{\text {eff }}$ is the effective complex skin depth. from numerical evaluations of the Sommerfeld integral, are essentially removed by correction factors which bring the MIM field into excellent agreement with the Sommerfeld field for $2 h / \delta \gtrsim 1$ (Michel, 1986; Bergeron et al., 1989). The first of these is a half-space correction, which we call a renormalization function $F$, defined as the ratio of the Sommerfeld to the MIM field for half-space models:

$$
F \equiv Z_{\mathrm{MIM}} / Z_{\mathrm{SOM}}
$$

For $\rho<h, F$ is fairly insensitive to $\rho$ and may be expressed as a function of $A=2 h / \delta$. For the survey discussed in this paper, $\rho=5 \mathrm{~m}$ and $h \simeq 20 \mathrm{~m}$. An analytic fitting function for the magnitude of $F$ is given by

$$
\begin{aligned}
1 & -|F|=0.9874 \exp [-1.5845 A]-0.01997 \\
& \times \exp [-0.18936 A]+0.04016 \exp [-0.50075 A],
\end{aligned}
$$

and the phase of $F$ is given in radians by

$$
\varphi=0.6766 \exp [-A / 1.016]+0.1102 \exp [-A / 3.064] .
$$

When $A$ is less than or much less than 1, the MIM field diverges from the Sommerfeld field. For the measured data described in this paper, $A$ is greater than 1. A multilayer correction factor is discussed in the next section.

\section{MULTILAYER MIM THEORY}

\section{Forward calculations}

The parameters of the forward layered model are embedded in $Q$, Wait's multilayer correction factor introduced in equation (1) and given for the two-layer model in equation (2). The expression for $Q_{12}$ assumes a plane-wave primary field. For the case where there is a lateral variation in the primary field, $Q_{12}$ is modified by a factor $\beta_{1}$ which was first introduced by Wait (1951) and is a measure of the scale of the lateral variation of the primary field relative to the first layer skin depth. The form of $\beta_{1}$ suggested by Wait is

$$
\beta_{1}=1 / 2\left(\delta_{1} / 2 L\right)^{2}
$$

where $L$ is some characteristic lateral distance over which the primary field varies.

In the case of an AEM system, the footprint of the device can serve as a measure of this lateral variation. The size of the footprint of an AEM system has been shown to be of the order of $2 h$ (Kovacs et al., 1995). Thus the $\beta$ factor is given approximately by $\beta_{1} \simeq 1 / 2\left(\delta_{1} / 4 h\right)^{2}=(1 / 8)(1 / A)^{2}$.

In numerical studies which treated $\beta$ as a correction factor for two-layer models that brings the MIM field into agreement with the corresponding Sommerfeld field, it was found empirically that $\beta_{1} \simeq 1 /\left(a_{1} A^{2}+a_{2} A\right)$, where $a_{1}$ and $a_{2}$ are tabular complex functions of first layer thickness (Michel, 1986). These results may be generalized to give $\beta$ approximately in terms of $R$ :

$$
\beta_{1} \simeq(1 / 8)\left(\delta_{1} / \rho R\right)^{2}
$$

where $R$ is given by equation (1) for forward calculations or equation (4) for inverse calculations. Following Wait (1951, 1991), the expression for the two-layer correction factor $Q_{12}$ with the $\beta_{1}$ factor included becomes

$$
Q_{12}=\left[G_{12}+\tanh \left(x_{1}\right)\right] /\left[1+G_{12} \tanh \left(x_{1}\right)\right],
$$


where $G_{12}=c_{12}\left[\left(1-i \beta_{1}\right) /\left(1-i \beta_{2}\right)\right]^{1 / 2}, x_{1}=(1+i)\left(1-i \beta_{1}\right)^{1 / 2}$ $y_{1}, y_{1}=d_{1} / \delta_{1}, \beta_{2}=(1 / 8)\left(\delta_{2} / \rho R\right)^{2}$, and $\delta_{2}$ is the skin depth of the second layer.

For a three-layer model,

$$
Q_{12}=\left[G_{12} Q_{23}+\tanh \left(x_{1}\right)\right] /\left[1+G_{12} Q_{23} \tanh \left(x_{1}\right)\right],
$$

where $Q_{23}=\left[G_{23}+\tanh \left(x_{2}\right)\right] /\left[1+G_{23} \tanh \left(x_{2}\right)\right], G_{23}=$ $c_{23}\left[\left(1-i \beta_{2}\right) /\left(1-i \beta_{3}\right)\right]^{1 / 2}, x_{2}=(1+i)\left(1-i \beta_{2}\right)^{1 / 2} y_{2}, y_{2}=$ $d_{2} / \delta_{2}, \beta_{3}=(1 / 8)\left(\delta_{3} / \rho R\right)^{2}$, and $\delta_{3}$ is the skin depth of the third layer.

The above relations can be generalized to

$$
\begin{aligned}
Q_{n, n+1}= & {\left[G_{n, n+1} Q_{n+1, n+2}+\tanh \left(x_{n}\right)\right] } \\
& /\left[1+G_{n, n+1} Q_{n+1, n+2} \tanh \left(x_{n}\right)\right] .
\end{aligned}
$$

where $G_{n, n+1}=c_{n, n+1}\left[\left(1-i \beta_{n}\right) /\left(1-i \beta_{n+1}\right)\right]^{1 / 2}, x_{n}=(1+i)(1-$ $\left.i \beta_{n}\right)^{1 / 2} y_{n}, y_{n}=d_{n} / \delta_{n}, \beta_{n+1}=(1 / 8)\left(\delta_{n+1} / \rho R\right)^{2}$, and $\delta_{n+1}$ is the skin depth of the $(n+1)$ layer.

The calculations of $Q_{i, j}$ and $G_{i, j}$ actually proceed from the bottom half-space to the top layer at each of the system frequencies. If the forward model has $m$ finite layers with the $(m+1)$ layer effectively a half-space, then the correction factor for the $m, m+1$ interface is given by

$$
Q_{m, m+1}=\left[G_{m, m+1}+\tanh \left(x_{m}\right)\right] /\left[1+G_{m, m+1} \tanh \left(x_{n}\right)\right],
$$

i.e., $Q_{m+1, m+2} \equiv 1$, and the calculation proceeds upward to the calculation of $Q_{12}$ by repeatedly using equation (11).

\section{Inverse calculations}

A value for $R$ is extracted from the AEM fields at each of the available frequencies using equation (4). By solving equation (1) for $Q$, experimental values for $Q$ are given by

$$
Q_{\exp }(f)=[\rho R(f)-2 h] /(1-i) \delta_{1}(f),
$$

and the inversion proceeds from the first layer down. To simplify the following analysis, we set $\beta_{n}=0$, so that $G_{n, n+1}=c_{n, n+1}$ and $x_{n}=(1+i) y_{n}$.

The data are ordered in terms of decreasing frequencies $f_{1}>f_{2}>f_{3}>\cdots$. We initially assume that $Q_{\exp }\left(f_{1}\right)=1$, i.e., $d_{1}>\delta_{1}\left(f_{1}\right)$, where $f_{1}$ is the highest frequency. (Later in the calculation, we check this assumption.) We then determine the system altitude $h$ and the skin depth of the first layer by inverting equation (1):

$$
h=\rho\left[\operatorname{Re} R\left(f_{1}\right)+\operatorname{Im} R\left(f_{1}\right)\right] / 2
$$

and

$$
\delta_{1}\left(f_{1}\right)=-\rho \operatorname{Im} R\left(f_{1}\right)
$$

Thus,

$$
\sigma_{1}=\left(\pi \mu_{0} \delta_{1}^{2} f_{1}\right)^{-1}
$$

Next, we assume that at $f_{2}, \delta_{\text {eff }}$ is modified by the second layer. Thus we equate $Q_{\exp }\left(f_{2}\right)$ to the forward expression for $Q_{12}$ given by equation (2). Equation (2) can be rewritten as

$$
Q_{12}=\tanh \left[\tanh ^{-1}\left(c_{12}\right)+x_{1}\right] .
$$

Then,

$$
\tanh ^{-1}\left(Q_{12}\right)=\tanh ^{-1}\left(c_{12}\right)+x_{1}
$$

We next use the identity $\tanh ^{-1}(z)=(1 / 2) \ln [(1+z) /(1-z)]$ to transform equation (2) into

$$
\begin{aligned}
& (1 / 2) \ln \left[\left(1-c_{12}\right) /\left(1+c_{12}\right)\right] \\
& \quad=x_{1}+(1 / 2) \ln \left[\left(1-Q_{12}\right) /\left(1+Q_{12}\right)\right],
\end{aligned}
$$

or

$$
\left(1-c_{12}\right) /\left(1+c_{12}\right)=\exp \left(2 x_{1}\right)\left(1-Q_{12}\right) /\left(1+Q_{12}\right) .
$$

Equation (16b) is complex, which requires that the real (imaginary) component of the left side equals the real (imaginary) component of the right side. Rationalizing the right side of equation (16b) into real and imaginary components results in

$$
\begin{aligned}
& \exp \left(2 x_{1}\right)\left(1-Q_{12}\right) /\left(1+Q_{12}\right) \\
& =\exp \left(2 y_{1}\right)\left[\left(a \cos 2 y_{1}-b \sin 2 y_{1}\right)\right. \\
& \left.\quad+i\left(a \sin 2 y_{1}+b \cos 2 y_{1}\right)\right],
\end{aligned}
$$

where $a=\left(1-\left|Q_{12}\right|^{2}\right) /\left(1+\left|Q_{12}\right|^{2}+2 \operatorname{Im} Q_{12}\right)$ and $b=$ $-2 \operatorname{Im} Q_{12} /\left(1+\left|Q_{12}\right|^{2}+2 \operatorname{Im} Q_{12}\right)$. Since the left side of equation (16b) is real, the imaginary component of the right side is zero. Thus

$$
y_{1}(f)=(1 / 2) \tan ^{-1}\left[2 \operatorname{Im} Q_{12}(f) /\left(1-\left|Q_{12}\right|^{2}\right)\right] .
$$

The parameter $c_{12}$ is then calculated from $Q_{12}$ and $y_{1}$ either by equating the real components or the magnitudes of equation (16b). The magnitude equality results in a slightly simpler relationship:

$$
\begin{aligned}
& \left(1-c_{12}\right) /\left(1+c_{12}\right)=\exp \left(2 y_{1}\right)\left[\left(1-\left|Q_{12}\right|^{2}\right)^{2}\right. \\
& \left.+\left(2 \operatorname{Im} Q_{12}\right)^{2}\right]^{1 / 2} /\left(1+\left|Q_{12}\right|^{2}+2 \operatorname{Im} Q_{12}\right) .
\end{aligned}
$$

Thus,

$$
c_{12}=(1-E) /(1+E),
$$

where $E$ is the right side of equation (19). Applying these results to the $f_{2}$ data, we see $y_{1}$ (hence $d_{1}$ ) and $c_{12}$ (hence $\sigma_{2}$ ) are given as

$$
y_{1}\left(f_{2}\right)=[1 / 2] \tan ^{-1}\left[2 \operatorname{Im}\left(Q_{\exp }\left(f_{2}\right)\right) /\left(1-\left|Q_{\exp }\left(f_{2}\right)\right|^{2}\right)\right]
$$

and

$$
c_{12}=\left(1-E\left(f_{2}\right)\right) /\left(1+E\left(f_{2}\right)\right) \text {. }
$$

More generally the forward expression for $Q_{n, n+1}$ given by equation (11) may be inverted to solve for $y_{n}\left(f_{n+1}\right)$ and $c_{n, n+1}$ :

$$
\begin{aligned}
y_{n}\left(f_{n+1}\right)= & {[1 / 2] \tan ^{-1}\left[2 \operatorname{Im} Q_{n, n+1}\left(f_{n+1}\right)\right.} \\
& \left./\left(1-\left|Q_{n, n+1}\left(f_{n+1}\right)\right|^{2}\right)\right], \\
c_{n, n+1}= & \left(1-E\left(f_{n+1}\right)\right) /\left(1+E\left(f_{n+1}\right)\right),
\end{aligned}
$$


where $E\left(f_{n+1}\right)=\exp \left[2 y_{n}\left(f_{n+1}\right)\right]\left[\left(1-\left|Q_{n, n+1}\left(f_{n+1}\right)\right|^{2}\right)^{2}+\right.$ $\left.\left(2 \operatorname{Im} Q_{n, n+1}\left(f_{n+1}\right)\right)^{2}\right]^{1 / 2} /\left(1+\left|Q_{n, n+1}\left(f_{n+1}\right)\right|^{2}+2 \operatorname{Im} Q_{n, n+1}\right.$ $\left.\left(f_{n+1}\right)\right)$.

$Q_{n, n+1}$ is calculated from lower order $Q$ s (higher frequencies), as we now demonstrate. For example, equation (10) is inverted to give $Q_{23}$ in terms of $Q_{\exp }\left(f_{3}\right), c_{12}$, and $y_{1}\left(f_{3}\right)$. Note that at any frequency, $Q_{\exp }$ is calculated from $R(f)$ by means of equation (13). Thus,

$$
Q_{12}\left(f_{3}\right) \equiv Q_{\exp }\left(f_{3}\right),
$$

and $Q_{23}\left(f_{3}\right)$ is given by

$$
\begin{aligned}
Q_{23}\left(f_{3}\right)= & \left(1 / c_{12}\right)\left\{1-F_{12}\left(f_{3}\right) \exp \left[x_{1}\left(f_{3}\right)\right]\right\} \\
& /\left\{1+F_{12}\left(f_{3}\right) \exp \left[x_{1}\left(f_{3}\right)\right]\right\},
\end{aligned}
$$

where $F_{12}\left(f_{3}\right)=\left(1-Q_{\exp }\left(f_{3}\right)\right) /\left(1+Q_{\exp }\left(f_{3}\right)\right)$. Recall that $x_{1}\left(f_{3}\right)=(1+i) y_{1}\left(f_{3}\right)=(1+i) y_{1}\left(f_{2}\right)\left(f_{2} / f_{3}\right)^{1 / 2}$. Thus, $y_{2}\left(f_{3}\right)$ and $c_{23}$ may be calculated from the value of $Q_{23}$ given by equation (24) using equations (22a) and (22b).

The general inverse expression for $Q_{n, n+1}$ in terms of previously calculated quantities is given by

$$
\begin{aligned}
& Q_{n, n+1}\left(f_{n+1}\right)=\left(1 / c_{n-1, n}\right)\left\{1-\exp \left[x_{n-1}\left(f_{n+1}\right)\right]\right. \\
& \left.\quad \times F_{n-1, n}\left(f_{n+1}\right)\right\} /\left\{1+\exp \left[x_{n-1}\left(f_{n+1}\right)\right] F_{n-1, n}\left(f_{n+1}\right)\right\}, \\
& F_{n-1, n}\left(f_{n+1}\right)=\left[1-Q_{n-1, n}\left(x_{n-1}\left(f_{n+1}\right), c_{n-1, n}\right)\right] \\
& \quad /\left[1+Q_{n-1, n}\left(x_{n-1}\left(f_{n+1}\right), c_{n-1, n}\right)\right],
\end{aligned}
$$

where $x_{n-1}\left(f_{n+1}\right)=x_{n-1}\left(f_{n}\right)\left(f_{n} / f_{n+1}\right)^{1 / 2}$, and $y_{n}\left(f_{n+1}\right)$ and $c_{n, n+1}$ are calculated using equations (22a) and (22b).

\section{Cutoff criteria}

As they are numerically calculated from the top layer downward, the $Q_{n, n+1}\left(f_{n+1}\right)$ must pass nonhalf-space criteria $\|\left. Q\right|^{2}-$ $1 \mid>\varepsilon$ and $|\operatorname{Im} Q|>\varepsilon$, where $\varepsilon$ is a small number. (For the results in this paper, $\varepsilon=0.01$ or 0.02 .) For example, suppose $Q_{34}$ is to be extracted from the $f_{4}$ data. If $\|\left. Q_{34}\left(f_{4}\right)\right|^{2}-1 \mid<\varepsilon$ for some point in the $f_{4}$ data stream, then that datum at $f_{4}$ is disqualified to calculate $Q_{34}$, and the calculation is terminated for this point. Thus $d_{3}$ and $\sigma_{4}$ and any lower layer thickness and conductivities are not calculated for this point.

\section{Corrections to the altitude and first layer conductivity}

If $\|\left. Q_{12}\left(f_{1}\right)\right|^{2}-1 \mid>\varepsilon$, where $Q_{12}\left(f_{1}\right)$ is calculated using equation (2), then corrected values for $h$ and $\delta_{1}\left(f_{1}\right)$ are obtained using

$$
R\left(f_{1}\right)=\left[2 h+(1-i) \delta_{1}\left(f_{1}\right) Q_{12}\left(f_{1}\right)\right] / \rho .
$$

This equation is inverted to give the first iteration corrected values for $h$ and $\delta_{1}\left(f_{1}\right)$ (hence $\left.\sigma_{1}\right)$ :

$$
\begin{aligned}
h(\text { cor })= & (\rho / 2)\left\{\operatorname{Re} R\left(f_{1}\right)+\operatorname{Im} R\left(f_{1}\right)\left[\operatorname{Re} Q_{12}\left(f_{1}\right)\right.\right. \\
& \left.\left.+\operatorname{Im} Q_{12}\left(f_{1}\right)\right] /\left[\operatorname{Re} Q_{12}\left(f_{1}\right)-\operatorname{Im} Q_{12}\left(f_{1}\right)\right]\right\}
\end{aligned}
$$

and

$$
\delta_{1}(\text { cor })=-\rho \operatorname{Im} R\left(f_{1}\right) /\left[\operatorname{Re} Q_{12}\left(f_{1}\right)-\operatorname{Im} Q_{12}\left(f_{1}\right)\right] .
$$

For example, if $\left|Q_{12}\left(f_{1}\right)-1\right|=\sqrt{ } 2|a|$, where $a$ is a small real number, then we may write $\operatorname{Re} Q_{12}\left(f_{1}\right) \cong(1+a)$ and $\operatorname{Im} Q_{12}\left(f_{1}\right) \simeq-a$. In this approximation, the fractional differences between the initial and corrected values of $h$ and $\sigma_{1}$ are given (to first order in $a$ ) by

$$
\Delta h / h \equiv\left(h-h_{\text {cor }}\right) / h_{\text {cor }} \cong-\left(\delta_{1} / h\right) a,
$$

and

$$
\Delta \sigma_{1} / \sigma_{1} \equiv\left(\sigma_{1}-\sigma_{1 \text { cor }}\right) / \sigma_{1 \text { cor }} \cong-4 a
$$

An iterative loop may be employed to further refine these corrections.

\section{Corrections to the lower layer thicknesses and conductivities}

In the calculations of $Q_{n-1, n}\left(f_{n}\right)$ described in the following section, it is assumed that $Q_{n, n+1}\left(f_{n}\right)$ is approximately equal to 1 . This assumption can be checked by calculating $Q_{n, n+1}\left(f_{n}\right)$ using the forward expression equation (11) after inverting $Q_{n, n+1}\left(f_{n+1}\right)$ for $y_{n}\left(f_{n+1}\right)$ and $c_{n, n+1}$. If $Q_{n, n+1}\left(f_{n}\right)$ passes the nonhalf-space test (e.g., $\left.|| Q_{n, n+1}\left(f_{n}\right)\right|^{2}-1 \mid>\varepsilon$ ), then a correction to the values of $y_{n-1}$ and $c_{n-1, n}$ is made in terms of $Q_{n, n+1}\left(f_{n}\right)$. Since $Q_{n, n+1}\left(f_{n}\right)$ is complex, the left sides of equations (16) for the $(n-1, n)$ interface become complex, with $c_{n-1, n}$ replaced with $c_{n-1, n} Q_{n, n+1}\left(f_{n}\right)$. The resultant magnitude equation for the $(n-1, n)$ inversion of equations (16) may be solved for a corrected value for $y_{n-1}\left(f_{n}\right)$ :

$$
\begin{aligned}
& y_{n-1}\left(f_{n}\right)(\text { cor })=(1 / 4) \ln \left\{\left[1-\left(c_{n-1, n}\left|Q_{n, n+1}\left(f_{n}\right)\right|\right)^{2}\right.\right. \\
& \quad+\left(2 c_{n-1, n} \operatorname{Im}\left(Q_{n, n+1}\left(f_{n}\right)\right)^{2}\right] /\left[1-\left|Q_{n-1, n}\left(f_{n}\right)\right|^{2}\right. \\
& \left.\quad+\left(2 \operatorname{Im}\left(Q_{n-1, n}\left(f_{n}\right)\right)^{2}\right]\right\}+(1 / 2) \ln \left\{\left[1+\left|Q_{n-1, n}\left(f_{n}\right)\right|^{2}\right.\right. \\
& \quad+\left(2 \operatorname{Re}\left(Q_{n-1, n}\left(f_{n}\right)\right)^{2}\right] /\left[1+2 c_{n-1, n} \operatorname{Re}\left(Q_{n, n+1}\left(f_{n}\right)\right.\right. \\
& \left.\left.\quad+\left(c_{n-1, n}\left|Q_{n, n+1}\left(f_{n}\right)\right|\right)^{2}\right]\right\} .
\end{aligned}
$$

Note for $Q_{n, n+1}\left(f_{n}\right)=1$, equation (28) reduces to the magnitude form of equation (16b). The parameter $c_{n-1, n}$ (cor) is given by equation (22b) using $y_{n-1}\left(f_{n}\right)$ (cor) in place of $y_{n-1}\left(f_{n}\right)$. The uncorrected value of $c_{n-1, n}$ is used for the initial calculation of $y_{n-1}$ (cor) in equation (28). An iterative loop may be introduced in which the $(i+1)$ th value for $y_{n-1}\left(f_{n}\right)$ is given in terms of the $i$ th value of $c_{n-1, n}$ (cor).

For the data analyzed in this paper, the corrections for $h$ and $\sigma_{1}$ have been included, but not the additional corrections to the lower layer thicknesses and conductivities. Preliminary calculations indicate that these corrections are small.

\section{Outline of multilayer inversion}

We summarize the inversion calculations in Table 1 for each frequency, starting with the highest frequency $f_{1}$. 


\section{INVERSION OF BARATARIA BAY DATA}

\section{Survey area}

The AEM survey is part of a multidisciplinary group effort whose overall intent is to study carbon transport dynamics in an estuarine environment, although this larger goal is not addressed in this paper. Figure 2 shows the survey area in Barataria Bay on the Louisiana Gulf of Mexico coast and the first day's flight lines. Both ground- and water-based conductivity measurements were made along flight lines 2 and 3 . We compare these measurements with the AEM inversion results (Bergeron et al., 1998b).

\section{Drift corrections}

Drift corrections to the raw data from the contractor were made by a linear interpolation procedure. High-altitude data recorded at the beginnings and ends of the flight lines provided a means of finding the system zero response (i.e., the endpoints for linear drift correction functions).

\section{Altitude determination}

The system laser altimeter was inoperative during the entire survey, and the global positioning system vertical-position recorder exhibited random excursions. Thus we were constrained to use the AEM altitude obtained from an inversion of the highest frequency data at $29970 \mathrm{~Hz}$ as the system altitude. For a half-space, there is excellent agreement between

\section{Table 1. Inversion calculations}

\begin{tabular}{|c|c|}
\hline Frequency & Calculations and inversion results \\
\hline$f_{1}$ & $\begin{array}{l}Q_{12}\left(f_{1}\right)=Q_{\exp }\left(f_{1}\right) \cong 1 \text {, the half-space as- } \\
\text { sumption. } R\left(f_{1}\right) \text { is inverted to give } h \text { and } \delta\left(f_{1}\right) \text {, } \\
\text { hence } \sigma_{1} \text {, equation }(14 \mathrm{c}) \text {. }\end{array}$ \\
\hline$f_{2}$ & $\begin{array}{l}Q_{\exp }\left(f_{2}\right) \text { is calculated from } R\left(f_{2}\right) \text {, equa- } \\
\text { tion }(13) . Q_{\exp }\left(f_{2}\right) \text { is inverted to give } y_{1}\left(f_{2}\right) \text {, } \\
\text { hence } d_{1} \text {, and } c_{12} \text {, hence } \sigma_{2} \text {, equations }(18),(19) \text {, } \\
\text { and }(20) . Q_{12}\left(f_{1}\right) \text { is calculated and corrected } \\
\text { values for } h \text { and } \delta_{1}\left(f_{1}\right) \text {, hence } \sigma_{1} \text {, are calculated, } \\
\text { equations }(27 \mathrm{a}) \text { and }(27 \mathrm{~b}) \text {. }\end{array}$ \\
\hline$f_{3}$ & $\begin{array}{l}Q_{\exp }\left(f_{3}\right) \text { is calculated from } R\left(f_{3}\right) \text {, equa- } \\
\text { tion }(13) . Q_{23}\left(f_{3}\right) \text { is calculated in terms of } \\
Q_{\exp }\left(f_{3}\right), y_{1}\left(f_{3}\right) \text { and } c_{12} \text {, equation }(24) \text {. } Q_{23}\left(f_{3}\right) \\
\text { is then inverted to give } x_{2}\left(f_{3}\right) \text {, hence } d_{2} \text {, het } \\
\text { and } c_{23}, \text { hence } \sigma_{3} \text {, equations }(22) \text {. Note that } \\
y_{1}\left(f_{3}\right)=y_{1}\left(f_{2}\right)\left(f_{2} / f_{3}\right)^{1 / 2} \text {. }\end{array}$ \\
\hline$f_{4}$ & $\begin{array}{l}Q_{\exp }\left(f_{4}\right) \text { is calculated from } R\left(f_{4}\right) \text {, equa- } \\
\text { tion }(13) . Q_{23}\left(f_{4}\right) \text { is calculated from } Q_{\text {exp }}\left(f_{4}\right) \text {, } \\
y_{2}\left(f_{4}\right) \text { and } c_{23} \text {, equation }(25) . Q_{34}\left(f_{4}\right) \text { is next } \\
\text { calculated in terms of } Q_{23}\left(f_{4}\right), y_{2}\left(f_{4}\right) \text { and } \\
c_{23} \text {, equation }(25) ; y_{2}\left(f_{4}\right)=y_{2}\left(f_{3}\right)\left(f_{3} / f_{4}\right)^{1 / 2} \text {. } \\
Q_{34}\left(f_{4}\right) \text { is then inverted to give } y_{3}\left(f_{4}\right) \text {, hence } \\
d_{3} \text {, and } c_{34} \text {, hence } \sigma_{4} \text {, equations }(22) \text {. }\end{array}$ \\
\hline \multirow[t]{2}{*}{$f_{n}$} & $\begin{array}{l}Q_{\exp }\left(f_{n}\right) \text { is calculated from } R\left(f_{n}\right) \text {, equa- } \\
\text { tion }(13) . Q_{23}\left(f_{n}\right) \text { is calculated from } Q_{\exp }\left(f_{n}\right) \text {, } \\
y_{1}\left(f_{n}\right) \text { and } c_{23} \text {, equation }(25) \text {. }\end{array}$ \\
\hline & $\begin{array}{l}Q_{n-1, n}\left(f_{n}\right) \text { is calculated from } Q_{n-2, n-1}\left(f_{n}\right), \\
x_{n-2}\left(f_{n}\right) \text { and } c_{n-2, n-1} \text {, equation }(25) \cdot Q_{n-1, n}\left(f_{n}\right) \\
\text { is then inverted to give } y_{n-1}\left(f_{n}\right) \text { hence } d_{n-1} \text { and } \\
c_{n-1, n} \text { hence } \sigma_{n} \text {, equation }(22) .\end{array}$ \\
\hline
\end{tabular}

laser altimeter readings and altitudes extracted from highfrequency AEM data using equation (14a) (Bergeron et al., 1989).

We have also calculated corrected values for the system altitude and first-layer skin depth which do not assume the first layer is a half-space at the highest system frequency. A value for $Q_{12}\left(f_{1}\right)$ is first obtained using the forward expression of equation (9) with values for $d_{1}$ and $c_{12}$ extracted from the AEM fields at the second frequency $f_{2} . Q_{12}\left(f_{1}\right)$ is then substituted in equations (27a) and (27b) to give corrected values for the altitude and the first layer skin depth at $f_{1}$. An iterative loop is used to produce further corrections to $h$ and $\sigma_{1}$.

In addition, $A=2 h / \delta_{1}$ is calculated from these results to determine $F(A)$, the half-space correction factor given by equation (6).

\section{Recalibration of data}

Conductivity-temperature-depth (CTD) profiles were collected at six locations along the portion of flight lines 2 and 3 which were over the Gulf. A recalibration of the data is required because of the disagreement between the measured AEM fields at the relatively deep-water location of CTD 6 and the forward AEM fields at the six experimental frequencies computed from the conductivity versus depth data measured at CTD 6 and the AEM system altitude at CTD 6. The solid line in Figure 3 is the conductivity versus depth measured at CTD 6 as the probe drifts down through the water column to the sea floor.

At CTD 6, the bottom is at a depth of $20 \mathrm{~m}$ and has a negligible effect on the AEM fields at all system frequencies except perhaps at the lowest $(270 \mathrm{~Hz})$. As shown later in shallower locations there is good indication that the bottom conductivity is $2-3 \mathrm{~S} / \mathrm{m}$. The resulting conductivity ratio of the seafloor to the bottom of the water column at $20 \mathrm{~m}$ results in a correction to the calculated AEM fields of less than $2 \mathrm{ppm}$ from the fields computed with the bottom conductivity assumed to be identical to the water conductivity at $20 \mathrm{~m}$. This is because the skin depths at the six system frequencies are all less than $20 \mathrm{~m}$. At the lowest frequency of $270 \mathrm{~Hz}$ and for a conductivity of $\sim 5 \mathrm{~S} / \mathrm{m}$, which is the conductivity of the water column from 10 to $20 \mathrm{~m}$, the skin depth is $\sim 13.5 \mathrm{~m}$.

The ratio of the calculated synthetic fields to the measured AEM fields at the CTD 6 location are the calibration constants that are given in Table 2. The amplitude of the complex field was multiplied by the amplitude correction factor, and the phase correction was added to the phase of the complex field at each frequency at each data point. Other investigators have reported using similar recalibration procedures on AEM data (Won and Smits, 1986; Smits and Won, 1987). Better calibration procedures for airborne AEM systems should be

Table 2. Calibration constants for the first day data.

\begin{tabular}{ccc}
\hline $\begin{array}{l}\text { Frequency } \\
(\mathrm{Hz})\end{array}$ & $\begin{array}{c}\text { Amplitude } \\
(\mathrm{ppm})\end{array}$ & $\begin{array}{c}\text { Phase } \\
\text { (radians) }\end{array}$ \\
\hline 270 & 0.76706 & 0.06677 \\
690 & 0.81544 & 0.07385 \\
1170 & 0.84621 & 0.06502 \\
4530 & 0.87912 & 0.06267 \\
11670 & 0.91194 & 0.04720 \\
29970 & 0.93371 & 0.02736 \\
\hline
\end{tabular}


developed, however. One possibility is to use sites whose conductivity/depth profile is known or measured in situ, such as reported in Fitterman and Deszcz-Pan (1997) and Deszcz-Pan et al. (1998). Such locations could be used to calibrate AEM systems following the procedures used in this investigation.

\section{Leveling of data}

Since the secondary field varies inversely to first order with the cube of the altitude, variations in the secondary field caused by vertical excursions of the AEM system often mask changes in the field associated with changes in the conductivity along the flight path as well as internal and external noise. The altitudeinduced variations in the secondary field may be removed by a continuation procedure (Bergeron et al., 1990, 1998a, 1999). The continuation of the field is accomplished by a linear translation of $R$, the first product of the inversion algorithm. The forward expression for $R$ in equation (1) shows that $R$ is linear in the altitude. Thus a value for $R$ at a common altitude $h_{0}$ can be calculated from $R(h)$, the value for $R$ extracted from the measured field at $h . R\left(h_{0}\right)$ is given by

$$
R\left(h_{0}\right)=R(h)+2\left(h_{0}-h\right) / \rho .
$$

The secondary field at $h_{0}$ is reconstructed using $R\left(h_{0}\right)$ in equation (3).

\section{Inversion results}

Figure 3 shows conductivity versus depth as measured at CTD 6, whose drop point was near the end of line 2. Also shown is the eight-layer approximation which was used as the forward model in the EMLOOPS program (Anderson, 1979) to calculate synthetic fields at the six system frequencies. The four-layer MIM inversion results of the EMLOOPS synthetic fields are also shown in the figure. The agreement between the forward and inverse model is good and gives confidence in the MIM inversion procedure.

Figure 4 shows a sample of data taken along flight line 2, whose flight direction is north to south along longitude $90.14^{\circ} \pm 0.003^{\circ}$, and which has a length of $51.4 \mathrm{~km}$. The starting latitude of line 2 is $29.434^{\circ}$, which is over the marsh, and the terminal latitude is $28.973^{\circ}$, which is over the Gulf. The gap

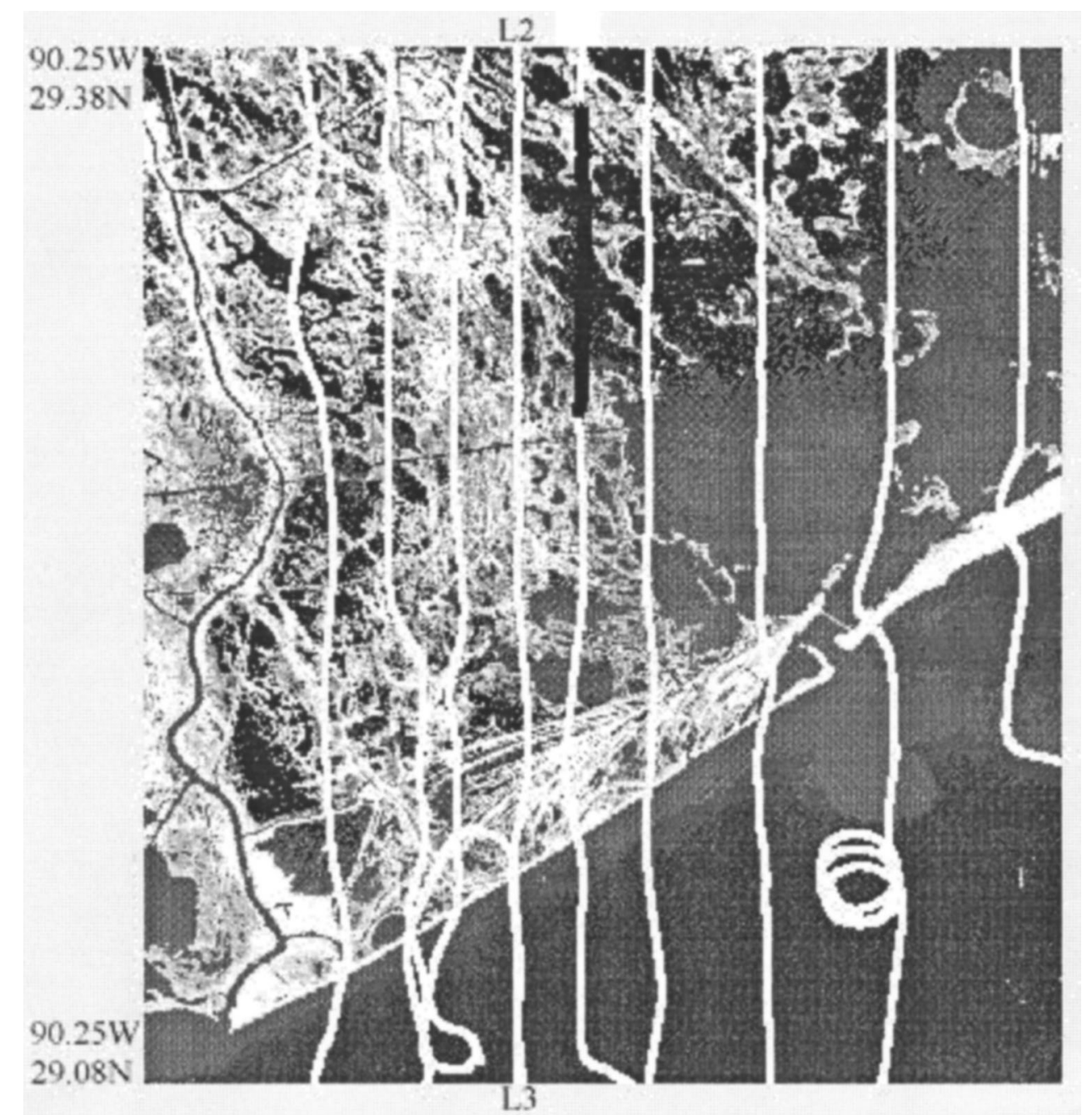

FIG. 2. Landsat image with first day's flight lines. Lines 2 and 3 are labeled. Line 3 tracks part of line 2, but in a south-to-north direction. 
in the data in the vicinity of latitude $29.2^{\circ}$ occurs where the helicopter rose to clear a set of power lines.

Notice the smooth portion of both continued components on the left side of Figure 4. This portion of the flight is over the Gulf of Mexico, where the variation in conductivity is negligible. This lack of variation in the continued field over the water indicates low internal and external noise for the AEM system. In contrast, the noticeable variation of the continued data over the marsh on the right side of the figure is caused by variations in the salinity and water content of the land/marsh.

Besides acquiring the system altitude $h$ from the $29970 \mathrm{~Hz}$ data, the near-surface conductivity $\sigma_{1}$ is also extracted from these data. Figure 5 shows the fractional changes or relative errors in $h$ and $\sigma_{1}$ produced by the correction procedure given by equations (27a) and (27b) and described above, as a function of latitude along line 2. The corrections to $\sigma_{1}$ and $h$ over the Gulf waters are consistent with the estimates provided by equations $(27 \mathrm{c})$ and $(27 \mathrm{~d})$.

Figure 6 compares the conductivity of the first layer $\sigma$ obtained from the MIM inversion along line 2 with surface probe measurements in the marsh and CTD surface values in the Gulf. The solid line plots the AEM surface conductivity $\sigma_{1}\left(f_{1}\right)$. The surface conductivities measured at 23 ground locations along line 2 with a conductivity probe (Dharmasri et al., 1997) are shown as open circles. Six CTD casts were made in the Gulf of Mexico near this line, and the surface CTD conductivities are plotted in Figure 6 as asterisks. The agreement between the AEM and ground-based conductivity measurements is good. Over the Gulf water, the agreement between the CTD and AEM measurements of surface conductivity is good in deeper waters (lower latitudes to the left) but not as good near shore. The CTD casts were made the day before the AEM flight, however, which might explain the disagreement between the near-shore surface CTD and the AEM results because of nearshore currents and mixing.

The effect of changing the cutoff criterion $\varepsilon$ is shown in Figure 7, which gives the depths of the first three layers for that portion of line 2 over the Gulf of Mexico. Compare the inversion results for the depth of layer 3 in the water column for a cutoff of 0.01 (top) with those for a cutoff of 0.02 (bottom). The points are more sparse for $\varepsilon=0.02$, which shows that the effective interface is fragile, i.e., $c_{34} \simeq 1$. Equation (21a) implies that $\left|\operatorname{Im} Q_{34}\left(f_{4}\right)\right|$ or $\left.|1-| Q_{34}\left(f_{4}\right)\right|^{2} \mid \leq 0.02$ for those points, and they are deleted from the calculation. When the depth of layer 3 merges with the bottom, the conductivity contrast becomes much greater, and fewer of the data points fail to satisfy the more stringent cutoff of 0.02 .

In Figures 8 and 9 we show the results of a multilayer inversion over the common flight path of lines 2 (dots) and 3 (crosses). Flight line 2 was recorded in a north-to-south direction. Flight line $3(16.4 \mathrm{~km})$ was recorded immediately following line 2 and retraces part of the path of line 2 in a south-tonorth direction. The shore is to the right of the figures and the Gulf of Mexico to the left. Figure 8 gives the layer depths in meters; Figure 9 gives the conductivities in siemens/meter of these layers. Inversion results for both layer depths and conductivities from both lines are almost identical, and it is difficult to distinguish the dots (line 2) and the crosses (line 3 ). The black solid line in Figure 8 is the depth of the bottom obtained by a linear interpolation between the last depth point at each of

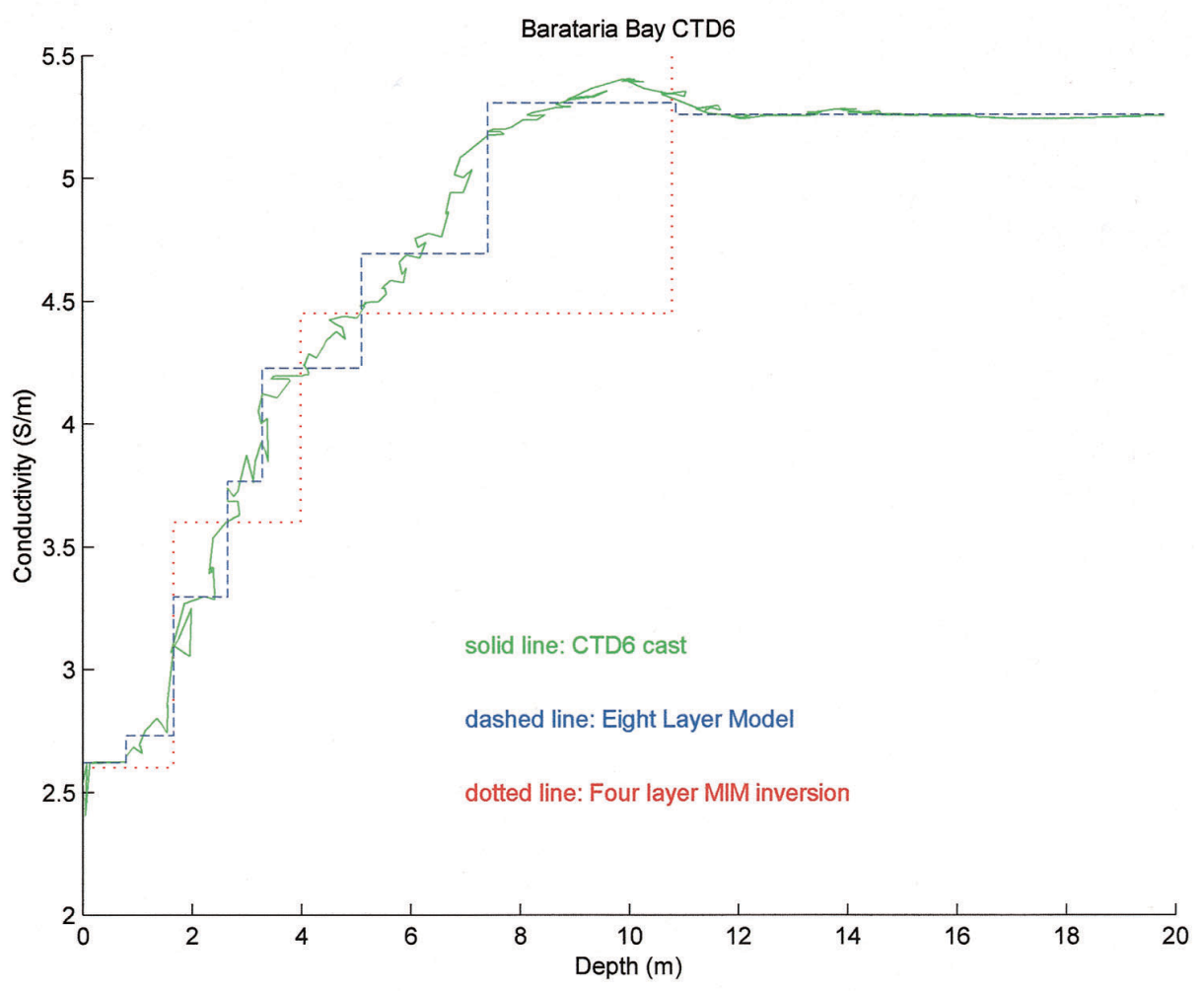

FIG. 3. Measured conductivity versus depth at CTD 6 (solid line), eight-layer step model (dashed line), and four-layer MIM inversion of model (dotted line). 
the six CTD locations. The locations of the 6 CTD casts are marked at the bottom of the figures. The bottom in Figure 8 is outlined in the shallow water first by the depth of the first layer and then by the second layer. As the water deepens, the third-layer depth follows the bottom until the water depth is greater than about $13 \mathrm{~m}$.

The surface conductivities from the ground truth measurements and the CTD casts previously shown in Figure 6 for all of line 2 are shown again in Figure 9 for the portion of line 2 coincident with line 3. As in Figure 8, it is difficult to distinguish the dots (line 2) from the crosses (line 3) as the results are almost identical. Furthermore, the blue open circles of the ground measurements (on the right of the figure) and the 6 blue asterisks of the CTD casts are practically hidden by the AEM symbols.

It can be seen in Figures 8 and 9 that, in the Gulf waters, the layer conductivities increase with depth until the AEM field penetrates the bottom, which results in a lower effective conductivity. The bottom conductivity is seen to become dominant in layer 4 (frequency $1770 \mathrm{~Hz}$ ) at a latitude of about $29.08^{\circ}$, which corresponds to a water depth of about $13 \mathrm{~m}$, where the third-layer depth merges with the bottom near CTD2. For depths greater than about $13 \mathrm{~m}$, the layer 4 conductivity approaches a constant value of about $4 \mathrm{~S} / \mathrm{m}$, the conductivity of the water column near the bottom. This results in the lowfrequency $Q$ s at $f_{5}$ and $f_{6}$ failing the cutoff procedure. In other words, there are no effective interfaces in the water column and, as noted before, the bottom produces a negligible effect on the low-frequency AEM fields.

The coincidence of the bottom with the depth of interface three shown in Figure 8 is not a result of a constraint on the inversion. The depth shown along the flight line was obtained from a linear interpolation of the six CTD bottom depths corrected for tidal changes at the time of the flight, and thus is an independent calculation. The good agreement of the inversion results from the data of lines 2 and 3 shown in Figures 8 and 9 is evidence of the stability of the AEM system and also demonstrates the robustness of the MIM inversion algorithms.

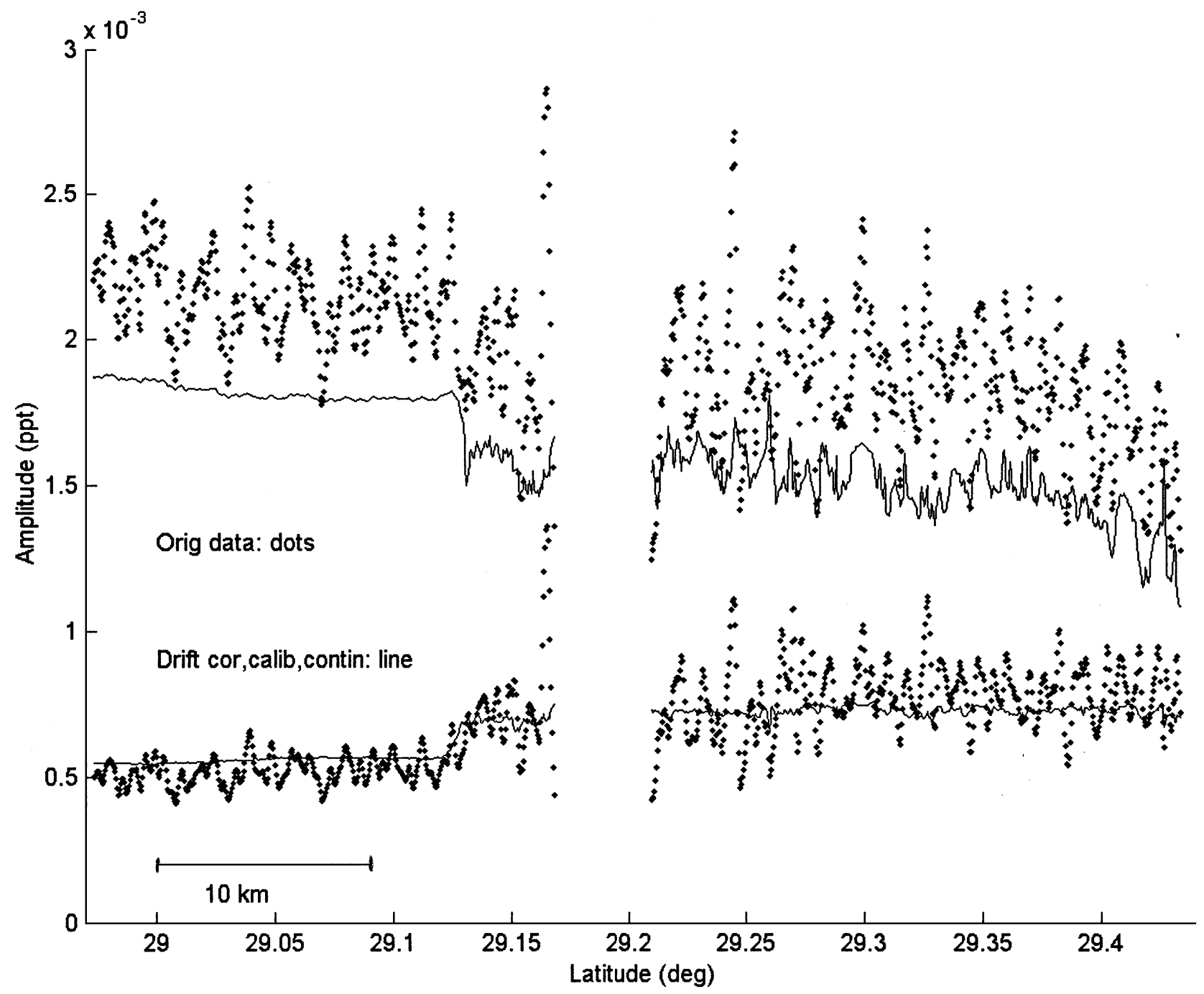

FIG. 4. AEM fields from line 2 at frequency $1770 \mathrm{~Hz}$ versus latitude. Dotted line: original data as received from contractor. Solid line: data that have been drift corrected, recalibrated, and continued to a common altitude of $18 \mathrm{~m}$. The upper and lower sets of curves are the inphase and quadrature fields (in parts per thousand), respectively. The right side of the figure is over the marsh; the central gap occurs when the helicopter rose to clear a set of power lines; the left side is over Gulf of Mexico waters. The scale bar is $10 \mathrm{~km}$ long. 


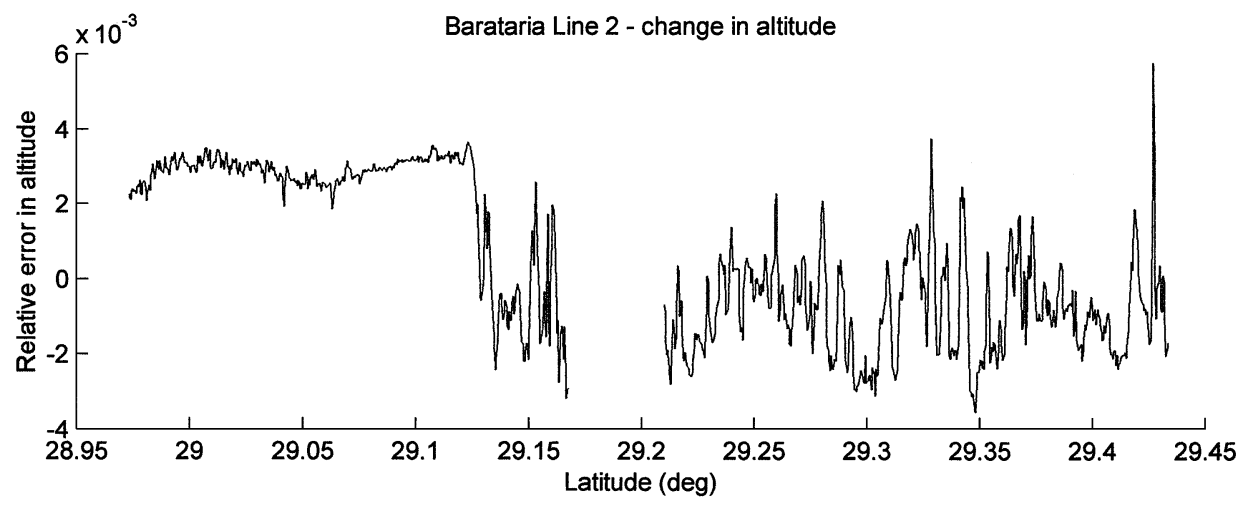

Barataria Line 2 - change in sigma1

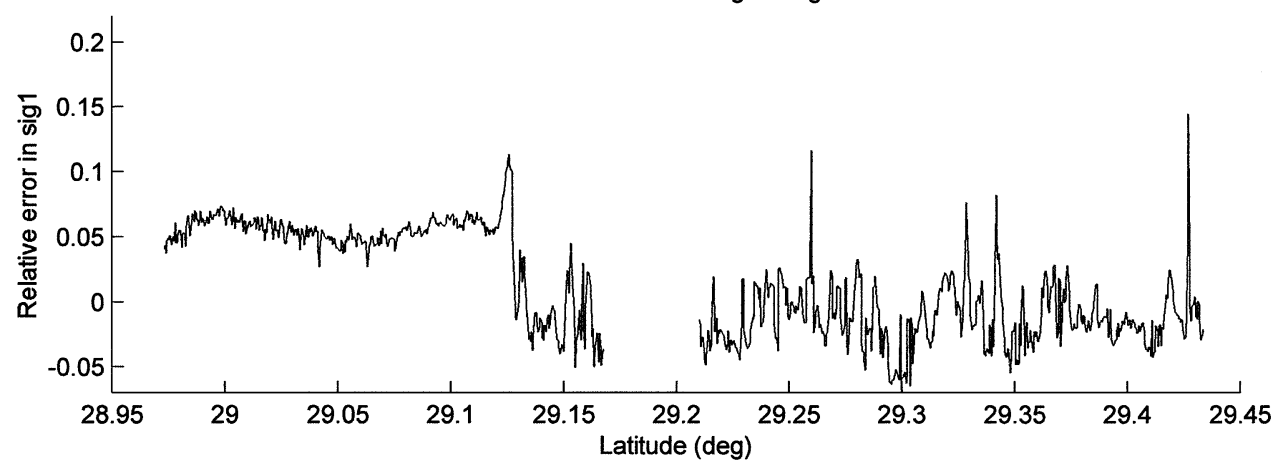

FIG. 5. Relative errors versus latitude along line 2. Top: altitude $h$. Bottom: first-layer conductivity $\sigma_{1}$.

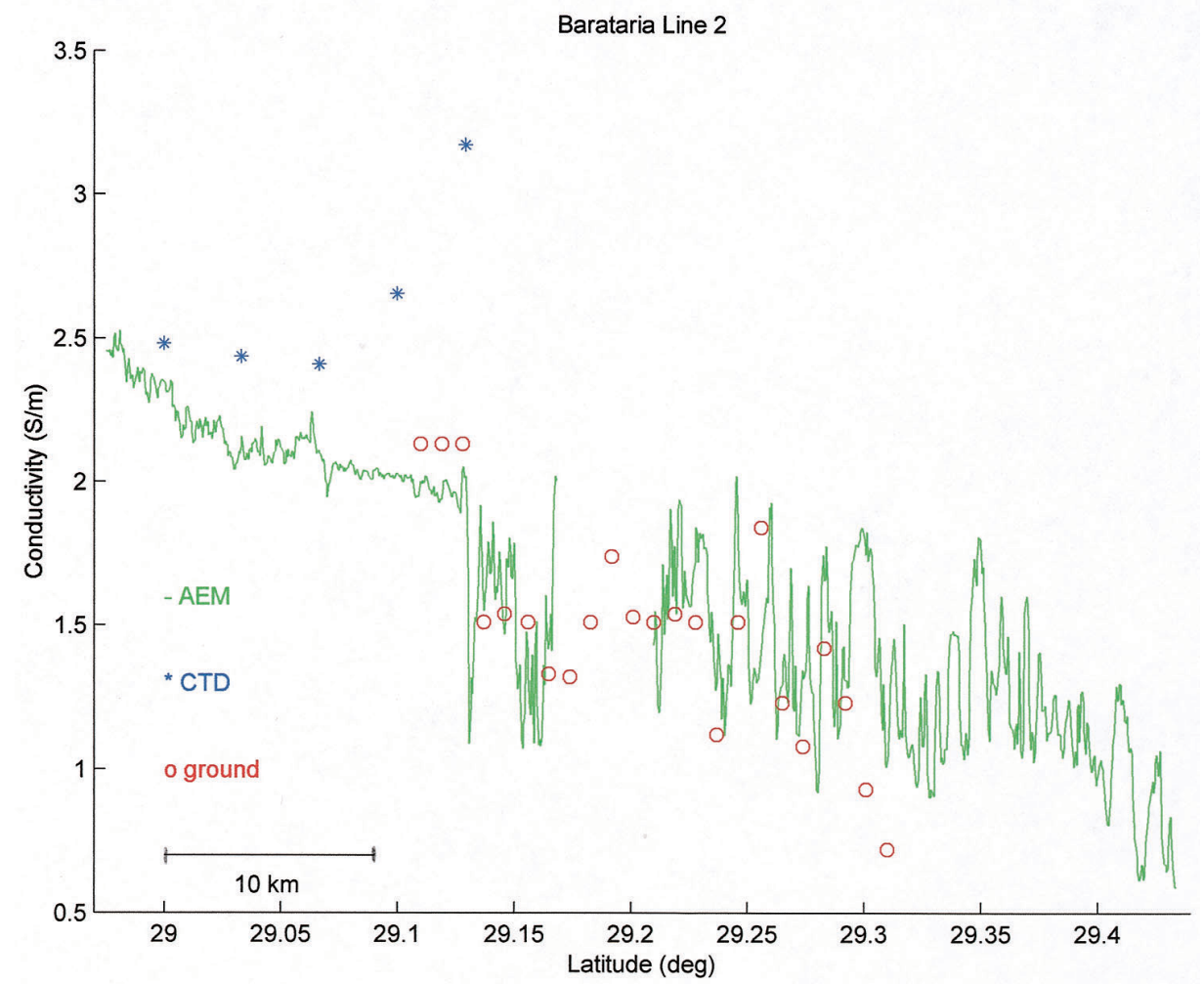

FIG. 6. Surface conductivities versus latitude along flight line 2. The solid line is the MIM inversion, the asterisks are CTD casts in the Gulf of Mexico, and the circles are surface conductivities measured on land. 
Figure 10 gives the measured conductivity versus depth at five CTD sites and the AEM inversion results for conductivity versus depth, showing a three or four layer stratification in the water column. Other regions in the marsh also show evidence of subsurface stratification in agreement with ground-based measurements (Bergeron et al., 1998a,b).

\section{CONCLUSIONS}

The good agreement of the MIM inversion model with the forward model used to generate synthetic calibration fields which were then inverted gives confidence in the MIM inversion algorithm. We have also found good agreement between
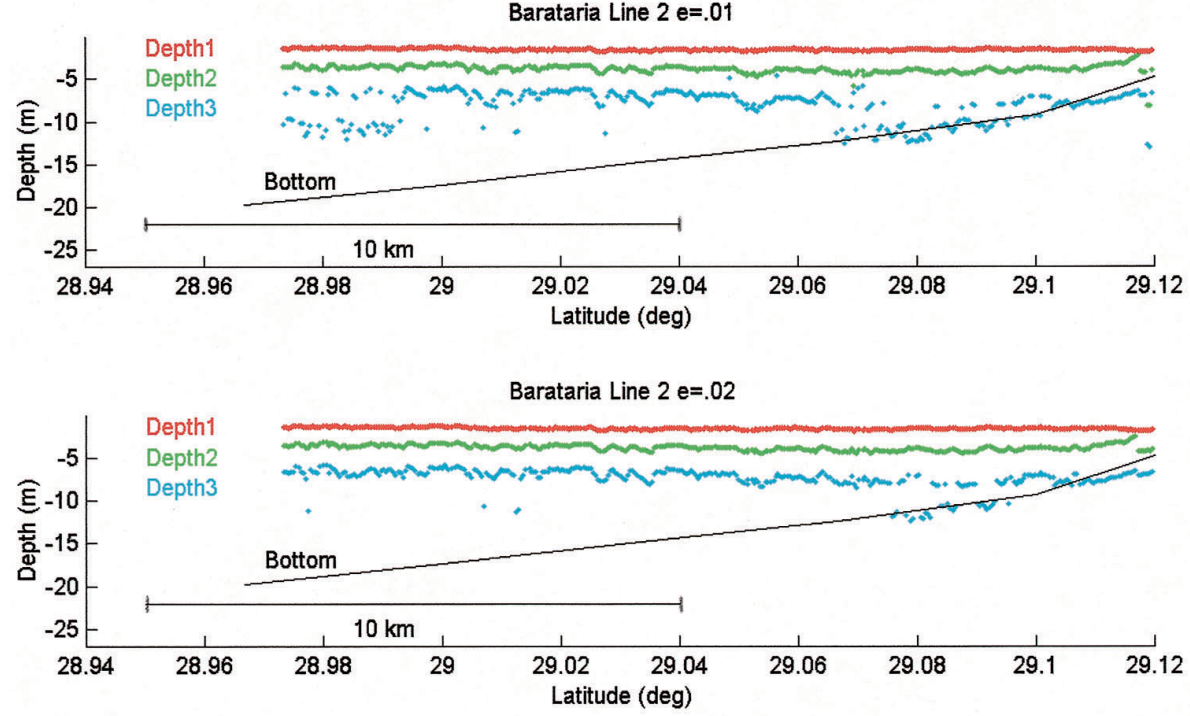

FIG. 7. Layer depths versus latitude from MIM inversions for a portion of line 2. Solid line is bottom depth from six CTD casts. Top: cutoff $\varepsilon=0.01$. Bottom: cutoff $\varepsilon=0.02$. The scale bar is $10 \mathrm{~km}$ long.

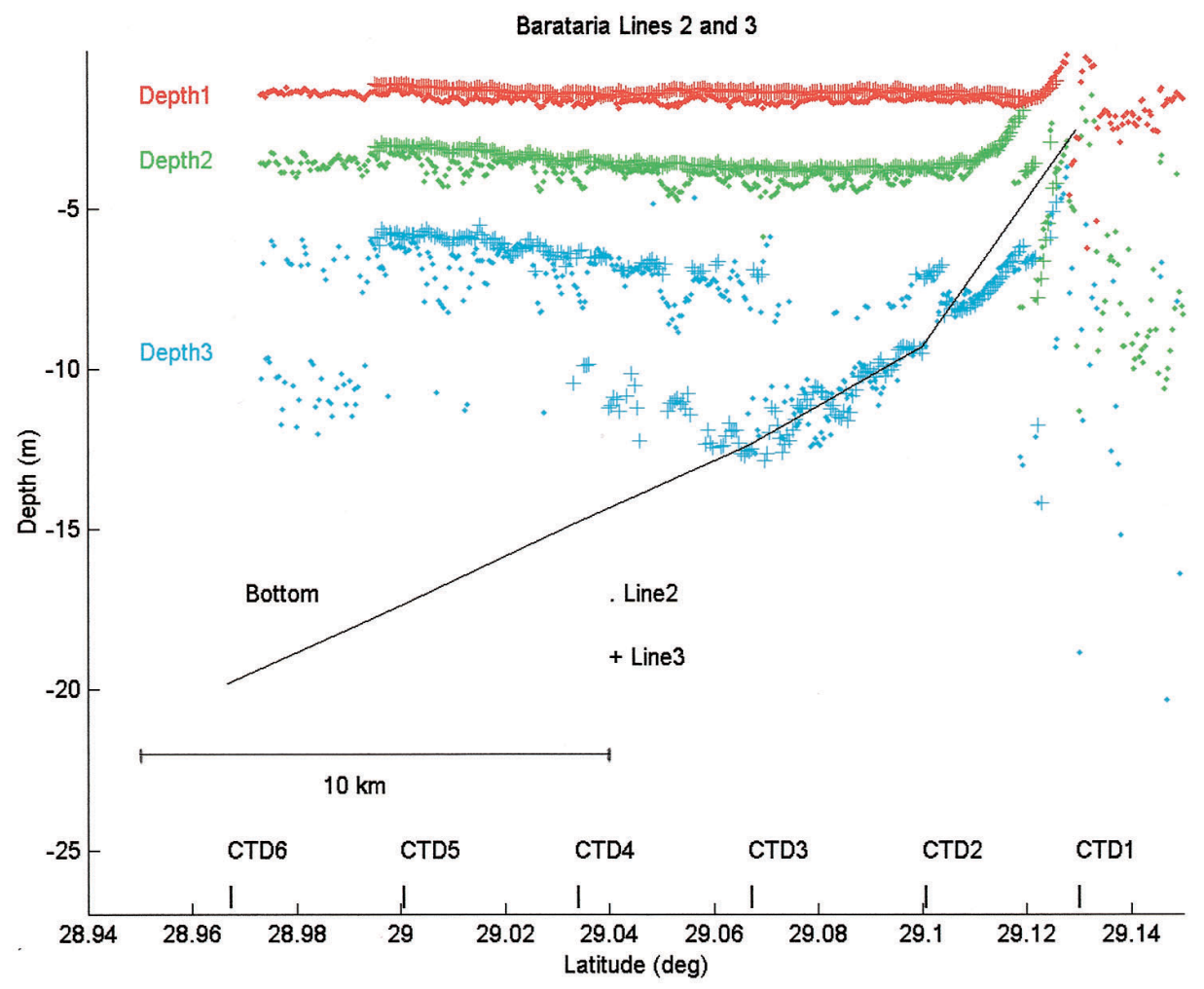

FIG. 8. Layer depths versus latitude from MIM inversions for a portion of line 2 (dots) and line 3 (crosses). Solid black line is bottom depth from six CTD casts. Depth of first layer shown in red, second layer in green, third layer in blue. The scale bar is $10 \mathrm{~km}$ long. 


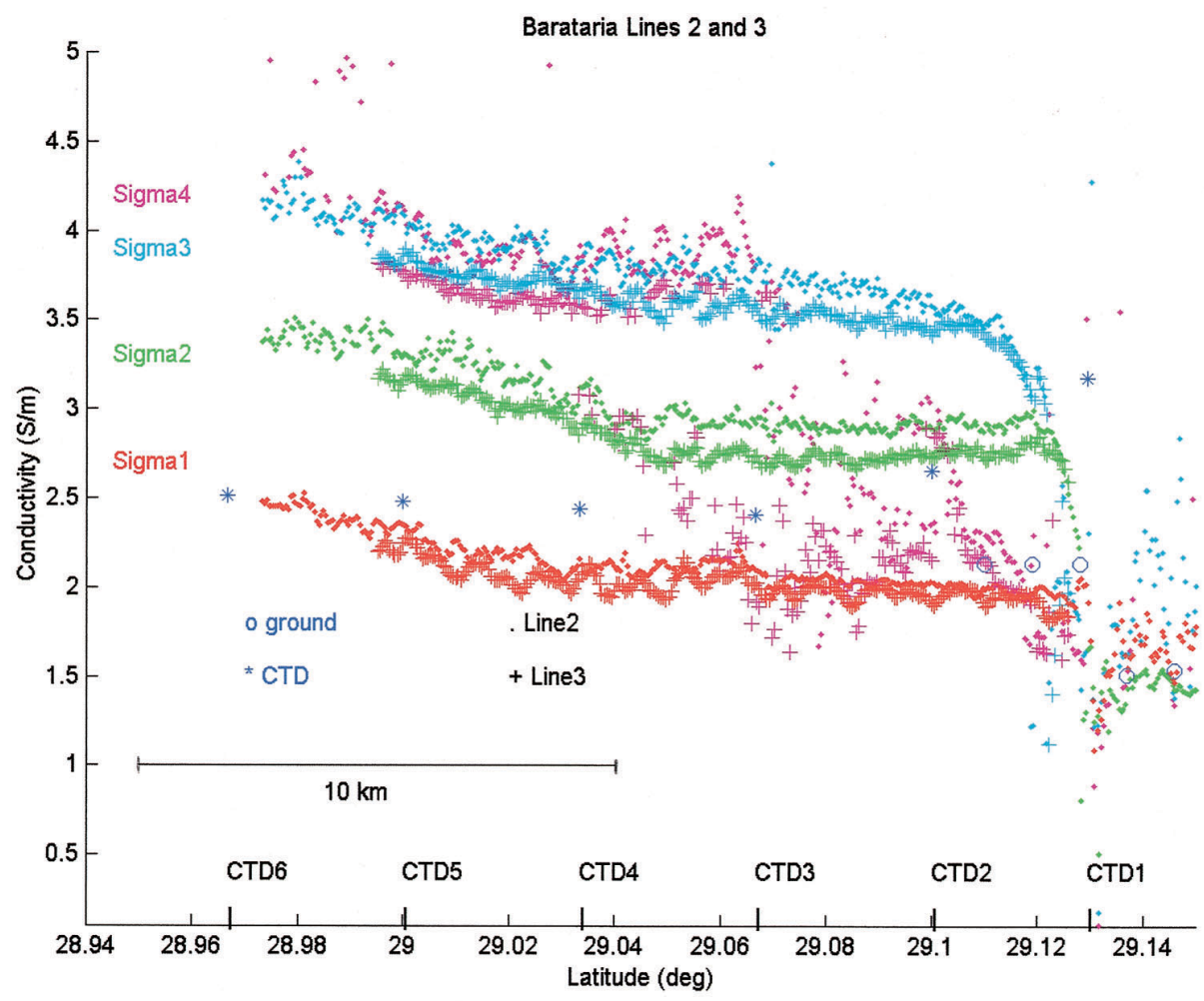

FIG. 9. Conductivities versus latitude from MIM inversions for a portion of line 2 (dots) and line 3 (crosses), surface conductivities from CTD casts (blue asterisks), and surface conductivities measured on land (blue open circles). Conductivity of first layer shown in red, second layer in green, third layer in blue, fourth layer in magenta. The scale bar is $10 \mathrm{~km}$ long.
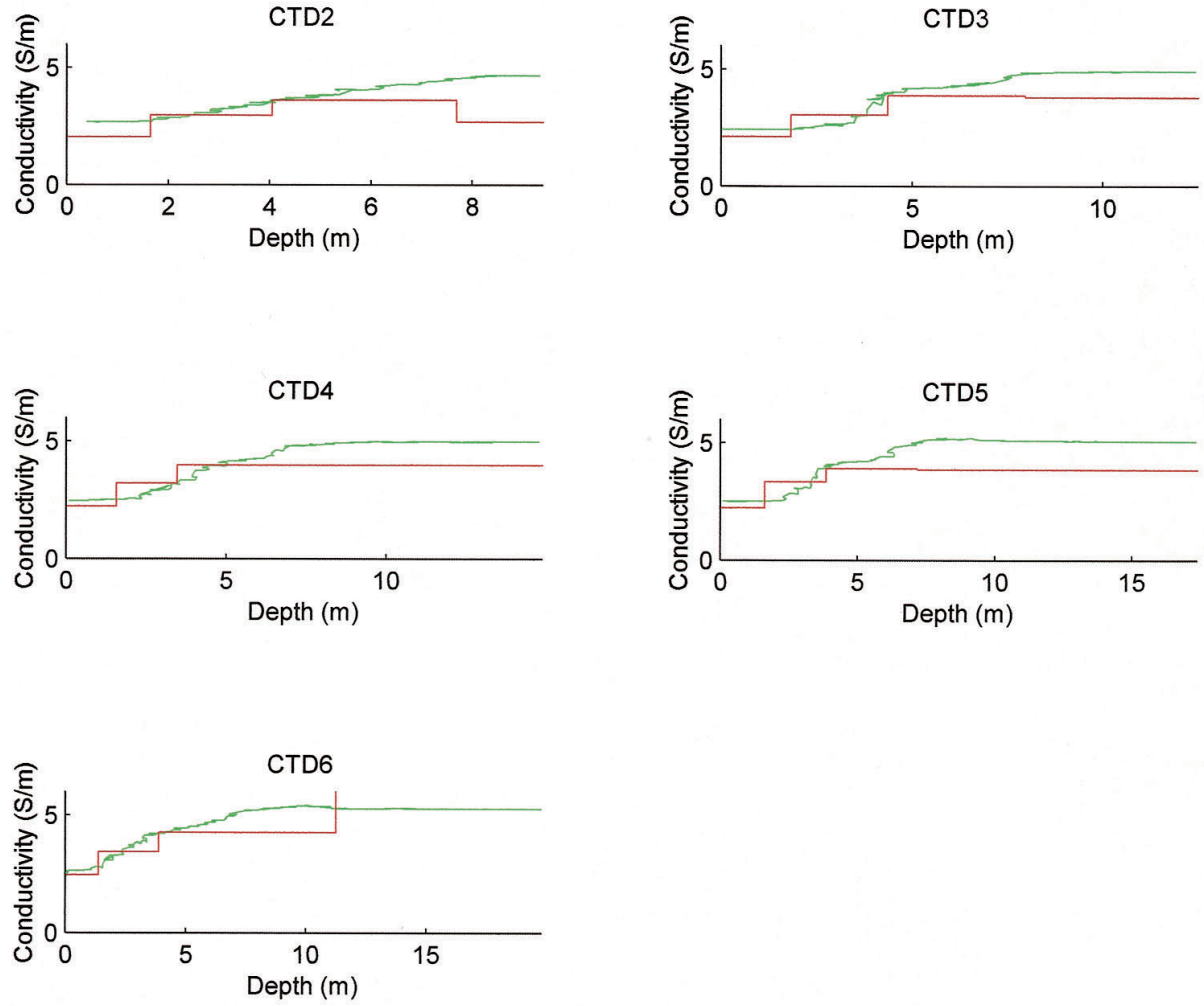

FIG. 10. Measured CTD cast (green) and MIM inversion conductivities (red) versus depth at five CTD sites. 
AEM inversion results, CTD casts in the Gulf of Mexico, and ground-based measurements over the marsh in the Barataria Bay estuary field example. Layered models adequately describe the conductivity stratification in nearshore Gulf waters. The excellent agreement of inversion results from lines 2 and 3 , which traversed the same flight path, gives confidence in the robustness of the MIM multilayer inversion algorithm and the stability of the AEM system.

\section{ACKNOWLEDGMENTS}

The authors acknowledge the support of a grant funded by NASA/EPSCoR. Greg Hymel and Melissa Whitten, University of New Orleans; Wayne H. Hudnall and L. Cecil Dharmasri, Louisiana State University Agricultural Center; Ramona Pelletier, NASA; and Larry Rouse, Louisiana State University, provided data and helpful discussions. Many thanks go to David Fitterman for his careful review of the original manuscript, which resulted in a much-improved version.

\section{REFERENCES}

Anderson, W. L., 1979, Program MARQLOOPS: Marquardt inversion of loop-loop frequency sounding: U.S. Geol. Surv. Open-File Report 790240.

Bergeron, C. J., Jr., 1986, Modified image method: Application to the response of layered Ohmic conductors to active electromagnetic sources: J. Appl. Phys., 59, 3901-3908.

Bergeron, C. J., Jr., Ioup, J. W., and Michel, G. A., II, 1989, Interpretation of airborne electromagnetic data using the modified image method: Geophysics, 54, 1023-1030.

Bergeron, C. J., Jr., Morris, T. L., and Ioup, J. W., 1990, Upward and downward continuation of airborne electromagnetic data: 60th Ann. Internat. Mtg., Soc. Expl. Geophys., Expanded Abstracts, 696699.

Bergeron, C. J., Jr., Ioup, J. W., Wu, Y., Ioup, G. E., Holladay, K. W., Hudnall, W. H., Dharmasri, L. C., and Pelletier, R. E., 1998a, Correlation of inversion results of AEM data with ground measurements in Barataria Bay, Louisiana: Proceedings of AEM 98, Internat. Conf. on Airborne Electromagnetics, 2.p2, 1-16.

Bergeron, C. J., Jr., Ioup, J. W., Wu, Y., Ioup, G. E., Holladay, K. W., and Hymel, G., 1998b, Comparison of inversion results from AEM data to field measurements in Barataria Bay, Louisiana, 68th Ann. Internat. Mtg., Soc. Expl. Geophys., Expanded Abstracts, 20242027.
Bergeron, C. J., Jr., Brusstar, J., Yi, N., Wu, Y., and Ioup, J. W., 1999, A new vertical continuation procedure for airborne electromagnetic field data from the modified image method: Geophysics, 64, 13641368 .

Deszcz-Pan, M., Fitterman, D. V., and Labson, V. F., 1998, Reduction of inversion errors in helicopter EM data using auxiliary information: Expl. Geophys., 29, 142-146.

Dharmasri, L. C., Hudnall, W. H., Pelletier, R. E., Bergeron, C. J., Holladay, K. W., Ioup, J. W., and Ioup, G. E., 1997, Spatial variability of coastal wetland soil characteristics within two salinity regimes: Ann. Mtg., Am. Soc. Agronomy, Agronomy Abstracts, 317.

Ellis, R. G., 1998, Inversion of airborne electromagnetic data: Expl. Geophys., 29, 121-127.

Fitterman, D. V., and Deszcz-Pan, M., 1997, Analysis of errors in HEM bird calibration: U.S. Geol. Surv. Report.

Fountain, D., 1998, Airborne electromagnetic systems-50 years of development: Expl. Geophys., 29, 1-11.

Frischknecht, F. C., 1967, Fields about an oscillating magnetic dipole over a two-layer earth, and application to ground and airborne electromagnetic surveys: Quart. Colorado School of Mines, 62.

Kovacs, A., Holladay, J. S., and Bergeron, C. J., Jr., 1995, The footprint/altitude ratio for helicopter electromagnetic sounding of seaice thickness: Comparison of theoretical and field estimates: Geophysics, 60, 374-380.

Michel, G. A., II, 1986, Development and application of self-correction methods for MIM inversion of AEM bathymetry data: M.S. thesis, Univ. of New Orleans.

Mozley, E., Kooney, T., Byman, D., and Fraley, D., 1991, Kings Bay airborne electromagnetic survey: Naval Oceanographic and Atmospheric Research Laboratory Report 019:352:91.

Pelletier, R. E., and Holladay, K. W., 1994, Mapping sediment and water properties in a shallow coastal environment with airborne electromagnetic profile data: Case study-the Cape Lookout, NC area: MTS J., 28, No. 2, 57-67.

Pelletier, R. E., and Wu, S. T., 1989, A preliminary evaluation of the airborne electromagnetic bathymetry system for characterization of coastal sediments and marsh soils: Technical Papers of the 1989 ASPRS/ACSM Annual Convention 3, 366-375.

Sengpiel, K. P., 1983, Resistivity depth mapping with airborne electromagnetic survey data: Geophysics, 48, 181-196.

Smits, K., and Won, I. J., 1987, Airborne electromagnetic bathymetry: Sea Technology, Feb., 16-22.

Sommerfeld, A. N., 1909, The propagation of waves in wireless telegraphy: Ann. Phys., 28, 665-736.

Wait, J. R., 1951, The magnetic dipole over the horizontally stratified earth: Can. J. Phys., 29, 577-592. 1991, Complex image theory-Revisited: The Radioscientist, $2,44-47$.

Won, I. J., and Smits, K., 1986, Characterization of shallow ocean sediments using the airborne electromagnetic method: IEEE J. Oceanic Engineering, OE-11, 113-122. 